\title{
Pontos passíveis de melhoria no método de projeto de produto de Pahl e Beitz
}

\author{
Improvements in the product development \\ method proposed by Pahl and Beitz
}

\author{
Fábio Morais Borges ${ }^{1}$ \\ Celso Luiz Pereira Rodrigues ${ }^{1}$
}

\begin{abstract}
Resumo: É um desafio acompanhar o ritmo imposto pela conjuntura atual, na qual inovações tecnológicas, maiores exigências do mercado e tantas outras características têm tornado as empresas mais ágeis naquilo que desenvolvem. Com isso, o processo de desenvolvimento de produtos tem se tornado perigoso à medida que pula etapas cruciais, em detrimento de mais rapidez na colocação do produto no mercado. Os modelos de desenvolvimento de produtos são a forma de sequenciar as etapas necessárias à concepção de um produto. Um dos mais conhecidos é o desenvolvido pelos alemães, Gerhard Pahl e Wolfgang Beitz, pertencentes à escola semântica de projeto. Ela é analisada, minuciosamente, neste artigo, e pontos que podem ser aperfeiçoados no intuito de oferecer maior segurança aos produtos por ela desenvolvidos, são propostos. Ao final, 11 pontos são apresentados como propostas de melhoria para o método estudado, seguidos de explicações e justificativas baseadas em bibliografia referente ao assunto.
\end{abstract}

Palavras-chave: Desenvolvimento de produtos. Segurança. Acidentes com produtos.

\begin{abstract}
Following the current pace, in which technological innovations, increased market demands, and other characteristics have provided companies with more agile production, is indeed a challenge. Thus, the product development process has become dangerous as it skips crucial steps to the detriment of putting products in the market sooner. Product development methods are a way to determine the necessary steps to design a product. One of the most known methods is that developed by Gerhard Pahl and Wolfgang Beitz, who belong to the semantic school of design. This method is analyzed in this research, and improvements that can be made to provide higher safety to the products developed are proposed. At last, 11 improvement proposals were presented for the studied method followed by explanations and justifications based on the literature on this subject.
\end{abstract}

Keywords: Product development. Safety. Accidents whit products.

\section{Introdução}

Uma das características marcantes no mundo atual é a velocidade das mudanças tecnológicas. Nas últimas décadas tem se notado, com bastante frequência, os impactos causados pelo avanço da tecnologia, nos diversos setores da economia. $\mathrm{O}$ ritmo acelerado no surgimento de novos nichos de mercado ou mesmo mudanças de tendências e desejos dos consumidores obriga, cada vez mais, as empresas a terem versatilidade no seu mix de produtos. Isso tem exigido que o Processo de Desenvolvimento de Produto (PDP) seja muito mais dinâmico e rápido. Surge então um problema, o de não promover um bom desenvolvimento de algumas atividades importantes benchmarking, engenharia reversa, prototipagem ou testes de resistência e segurança - por levarem um certo tempo para serem realizadas (HALE;
KIRWAN; KJELLÉN, 2007; DILLENBURG, 2005; KINDLEIN JÚNIOR; PLATCHECK; CÂNDIDO, 2003; GUBER, 1998). Assim, geralmente, em função da velocidade de lançamento do produto no mercado, os testes são omitidos, deixando-se para promover mudanças, posteriormente, caso haja falhas no projeto original. Essa dinâmica do mercado faz com que o desenvolvimento de produtos seja bastante arriscado, pois provoca alterações de natureza organizacional e tecnológica nas Empresas, com aumento de fatores a serem gerenciados em um espaço temporal cada vez menor. Um ambiente com crescente complexidade. Essa complexidade vem dificultando o entendimento, o controle e o gerenciamento dos processos de desenvolvimento de produtos (ESTORILIO; SZNELWAR, 2001).

\footnotetext{
${ }^{1}$ Universidade Federal da Paraíba - UFPB, E-mails: fabiomoraisb@gmail.com; celsoluiz@ct.ufpb.br

Recebido em 11/3/2008 — Aceito em 9/3/2010
}

Suporte financeiro: Capes. 
Para Kruglianskas (1992), muitas empresas brasileiras desenvolvem seus produtos empiricamente, utilizando um sistema de informações deficiente que, muitas vezes, repete os mesmos erros de projeto. Aqui reside o grande problema dessa conjuntura toda que se criou. Por vezes, essas falhas acontecem quando da utilização do produto e, pior ainda, têm como consequência incidentes ou mesmo acidentes. Outros autores fazem referência a essa preocupação (RAUSAND; UTNE, 2009; COULIBALY; HOUSSIN; MUTEL, 2008; BARAM, 2007; FORMOSO; GUIMARÃES; SAURIN, 2002) e discutem medidas preventivas a serem adotadas no Planejamento do Produto - atividade que antecede o Processo de Desenvolvimento do Produto. Daí a importância de se estudar os Métodos de desenvolvimento de produtos, buscando incorporar, desde as fases iniciais, a preocupação com a segurança que eles oferecerão aos seus usuários.

A escola alemã de projeto de produtos, representada por autores como Neudörfer, Hundal, Roth, Koller, Rodenacker e pela VDI 2222 - Verein Deutscher Ingenieure -, tem estudado métodos de desenvolvimento de novos produtos, porém, dentre todas, a sistemática criada por Gerhard Pahl e Wolfgang Beitz é considerada clássica na área de projeto de produtos industriais e tem sido utilizada como base para várias pesquisas (MARINI; ROMANO, 2009; MAIER; FADEL, 2009; MENDES; BACK; OLIVEIRA, 2009; MENDEZ, 2004; FONSECA; NASCIMENTO; PADILHA, 2003; GOUVINHAS; COSTA, 2003; HOFFMEISTER, 2003).

Aliando a preocupação com o desenvolvimento de produtos mais seguros à importância do Método proposto por Gerhard Pahl e Wolfgang Beitz, este artigo tem como objetivo fazer uma análise deste Método e apresentar pontos passíveis de melhoria na busca pelo projeto de produtos mais seguros aos usuários. Consequentemente, desloca-se essa preocupação para as fases iniciais do PDP. O artigo não tem a intenção de diminuir a importância do Método e impedir sua utilização, e sim buscar melhorá-lo ainda mais, seguindo o direcionamento da segurança, como um processo de Design for Safety (DfS). E nisso se apoia a visão prevencionista seguida na análise do Método estudado, feita pelos autores deste artigo.

A seguir, faz-se uma breve apresentação dos conceitos abordados no artigo e justifica-se a escolha do Método de Desenvolvimento de Produtos estudado. Por fim, os onze pontos passíveis de melhoria, referentes à segurança, são apresentados, com as devidas justificativas para tal.

\section{Fundamentação}

\subsection{Produtos}

Dependendo da área, o termo produto pode receber definições bem diferentes. Mas as definições voltadas à área industrial e administrativa são as mais utilizadas. Mesmo assim, dentro destas áreas existem conceitos a respeito de produtos que devem ser apresentados para que se percebam e se entendam as diferenças e semelhanças entre as definições.

Com um conceito mais voltado para o comércio, Kotler (1998) já define o termo produto amplo ou expandido como sendo aquele conjunto de produtos e serviços agregados que acompanham o produto em si. Seria a imagem, a garantia, o serviço de entrega, o valor cultural e assim por diante. A definição de Costa (1987), além do exposto por Kotler, apresenta algumas especificações das características do produto. Para ele, produto compreende um complexo de atributos tangíveis (cor, embalagem, desenho industrial etc.) e intangíveis (reputação da marca, imagem do produto e do fabricante, serviços pós-venda etc.) que o consumidor analisa ao decidir satisfazer suas necessidades e/ou desejos. Algo que é tido como objetivo de qualquer Empresa. Outro objetivo é seu próprio crescimento. Unindo estes dois interesses, Cardoso (1985) afirma que o produto é o meio de atingir objetivos duplos de maximizar tanto a satisfação do consumidor como da organização.

Hoje em dia é até difícil imaginar uma empresa que não ofereça serviços de pós-venda, garantias e outras facilidades relacionadas a seus produtos. Porém, nem sempre foi assim. E não é necessário ir muito longe. Até meados da década de 80, o produto era encarado apenas como o final de uma cadeia produtiva, sem se obervar a adequação aos seus usuários. Porém, estudos (WRIGHT; SILVA; SPERS, 2009; LANGERAK; HULTINK, 2008; TOLEDO et al., 2008) têm mostrado que a área de Projeto / Desenvolvimento de Produto, até então esquecida ou marginalizada, passou, em algumas décadas, a ter maior espaço no planejamento estratégico de Empresas mais visionárias, recebendo investimentos e maior atenção dos níveis mais elevados das Organizações.

\subsection{Segurança}

A história da segurança não é tão atual quanto se pode pensar. Associar o seu surgimento somente ao desenvolvimento industrial, com a Segurança do Trabalho, é ceifar tudo que serviu de base para que hoje ela seja aceita e conceituada como uma área riquíssima do conhecimento humano em diversas esferas e, acima de tudo, necessária à qualidade de vida, como já pregava Maslow (1970) em sua Pirâmide das necessidades humanas (Figura 1), quando localizou a sensação de sentir-se seguro próxima à base dessa pirâmide (necessidades fisiológicas).

Ressalte-se que Maslow não fez menção a necessidades de estratos específicos da população, como trabalhadores, idosos, homens ou mulheres, e sim, chamou-a de Teoria da Motivação Humana, 


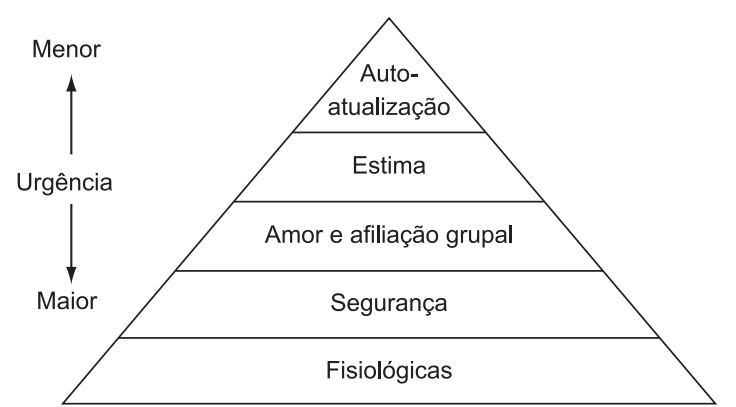

Figura 1. Pirâmide da hierarquia das necessidades. Fonte: Maslow (1970).

sendo o mais abrangente possível. E, como a segurança deve existir para situações tanto de trabalho como usuais do nosso cotidiano, a preocupação com aquilo que manuseamos e fazemos uso também deve ser enfocada. Produtos devem ser seguros àqueles que irão utilizá-los, independente de serem produtos de uso profissional (ferramentas, aparelhos de teste, máquinas etc.) ou não profissional (eletrodomésticos, eletroeletrônicos, produtos de limpeza, utensílios domésticos etc.).

\subsection{Segurança em produtos}

Produtos de consumo mais comum, como eletrodomésticos, brinquedos, ferramentas entre outros, dos quais o usuário muitas vezes não tem conhecimento técnico ou mesmo omite a leitura prévia de instruções sobre o uso do produto, são um campo fértil de oportunidades em que, a qualquer momento, uma falha pode ocasionar um acidente com consequências indesejadas e muitas vezes, desastrosas.

Para Sell (1992), segurança é regra básica na concepção de produtos e instalações e engloba tanto a execução confiável das funções técnicas por parte do produto, como também a redução dos riscos para as pessoas e o meio ambiente. Assim, identificar possíveis problemas de segurança nos produtos é permitir a compreensão de como os fatores e as circunstâncias estão interagindo com eles e avaliar as condições em que estão sendo utilizados, não apenas reduzindo os riscos a seus usuários, mas propiciando que desempenhem as funções para as quais foram desenvolvidos.

A percepção dos usuários quanto à segurança que as empresas oferecem a seus funcionários vem se tornando um diferencial na hora de escolher um determinado produto ou serviço. Em uma pesquisa realizada com cerca de 12 mil consumidores europeus, pela Corporate Social Responsibility (CSR), em 2000, $70 \%$ dos entrevistados responderam que proteger a saúde e a segurança de seus trabalhadores era uma área importante para o suporte das companhias (LÓPEZ-VALCÁRCEL, 2002).

Além disso, o impacto negativo que um acidente associado a um de seus produtos pode ocasionar é, por si só, um risco elevado, que pode definir entre a aceitação da empresa por parte do mercado ou sua rejeição. Podendo ainda vir acompanhada de alguma implicação jurídica, pois, como colocam muito bem Sicsú, Correia e Sena (2006), a partir do momento em que sai de suas fábricas, a empresa é responsável pela qualidade e conformidade de todo e qualquer produto por ela distribuído.

Muitas vezes não se faz a devida relação entre riscos do processo e seu projeto, como é endossado por Taylor (2007), quando afirma que o erro do projeto é uma das causas mais frequentes da falha de sistema e dos acidentes nas indústrias de processos, mas não obstante tem sido negligenciado pela maior parte das análises do risco de sistemas de processo e de controle. Os trabalhos de Clark e Fujimoto (1991) e de Rozenfeld et al. (2006) demonstram que as escolhas ocorridas no início do ciclo de desenvolvimento são responsáveis por cerca de $85 \%$ do produto final.

As taxas de falhas no desenvolvimento de novos produtos (DNP) são alarmantes, além de ser um processo caro e arriscado com uma grande parcela do custo total indo para eliminação e reparo de falhas nesses produtos. De acordo com Cooper (2001), nas companhias dos Estados Unidos, em média, $40 \%$ do DNP apresenta falha de projeto. Esta taxa varia entre $25 \%$ e $45 \%$, mas pode chegar a $90 \%$, dependendo de seu setor industrial. Estima-se que $46 \%$ dos recursos totais gastos em pesquisa e desenvolvimento foram desperdiçados em produtos que falharam. Reforçando a importância das fases iniciais, de acordo Masing apud Pahl et al. (2005), 80\% de todas as falhas são devidas ao desenvolvimento, projeto e planejamento deficientes, assim como $60 \%$ de todas as quebras dentro do período de garantia têm sua origem em desenvolvimentos imaturos e falhos.

Um estudo da Boeing examinou 232 acidentes com seus aviões comerciais, no período de 1982 a 1991 e constatou que a simples melhoria do projeto era uma estratégia de prevenção de acidentes em $20 \%$ de todos os casos, sugerindo que a omissão ou a falha deste projeto era uma causa para $20 \%$ destes acidentes (KINNERSLEY; ROELEN, 2007). Eles analisaram ainda 35 relatórios de investigação de acidentes na aviação e 13 relatórios de incidentes em plantas nucleares, em diversos países, e concluíram que o projeto tem influência em aproximadamente $50 \%$ destes eventos.

\subsection{Desenvolvimento de produtos}

Fica assim claro que produtos devem ser desenvolvidos com uma atenção muito grande no que 
concerne à sua utilização por parte dos consumidores, seja pela responsabilidade que as empresas têm sobre aquilo que disponibilizam ao mercado, por zelo de sua imagem ou mesmo pela busca de um processo contínuo de evolução no desenvolvimento de seus produtos. O desenvolvimento de novos produtos é considerado como um processo composto de diversas fases. À medida que estas fases transcorrem, o nível de detalhamento deste processo é consideravelmente aumentado, requerendo decisões para diminuir o número de alternativas para materializar o objeto de desenho (ROZENFELD, 1999). E como frisam Pahl et al. (2005), tudo isso passa por um procedimento para desenvolvimento de boas soluções, que seja planejável, flexível, otimizável e verificável, face à grande importância do desenvolvimento de um produto no momento certo e que desperte interesse por parte do mercado, tendo como uma das nomenclaturas, processo de projeto ou simplesmente, projeto.

\subsection{Método criado por Gerhard Pahl e Wolfgang Beitz (PAHL et al., 2005)}

O método tomado como referência foi o criado por dois alemães, Gerhard Pahl e Wolfgang Beitz, que não foge às características presentes na escola alemã do projeto de engenharia, inserida na escola semântica de filosofia de projeto. Nela, qualquer sistema técnico pode ser visto como um sistema que transforma grandezas de entrada em grandezas de saída, do tipo material, energia e informação.

Duas características principais podem ser extraídas do Método estudado. Na primeira, um problema é entendido como uma estrutura composta por entradas, uma função global e sua fronteira e por saídas, análogo à Teoria Geral dos Sistemas (BERTALANFFY, 1969), base da engenharia de produção. Para os autores, essa função global - ou total - pode ser desdobrada em subfunções que se relacionam e, muitas vezes, dependem umas das outras para serem ativadas, criando uma estrutura de elementos parciais que representam a Função Total (Figura 2). Além disso, essa estrutura que se cria deve prosseguir até que as subfunções não possam mais ser decompostas. Com isso, procura-se otimizar a resolução do problema global, buscando soluções parciais, para cada subfunção.

A segunda característica diz respeito à abordagem seguida por eles para um projeto de engenharia, assumindo-o como uma atividade sistemática estruturada, com etapas bem definidas e métodos a serem utilizados em cada uma delas. A seguir são descritas, sucintamente, as fases propostas no Modelo de Gerhard Pahl e Wolfgang Beitz.

A primeira fase é o Planejamento e Esclarecimento da Tarefa de Projeto. Nesta etapa se analisa a situação do mercado, da empresa e da conjuntura. Serão levantadas as necessidades a serem atendidas, venham elas como pedidos de desenvolvimento, sob a forma de um produto por parte do setor de planejamento de produtos, como pedidos de um cliente ou mesmo como críticas ou sugestões. Ao final desta etapa, busca-se elaborar uma lista detalhada de requisitos que contenha as restrições e os objetivos a serem alcançados, além de uma descrição do desejo ou exigência requerido pelo cliente.

A segunda seria o Projeto Conceitual. Um dos primeiros passos dessa fase é analisar a função global a ser desempenhada. Dependendo do produto, a função global pode ser bem complexa. Uma função complexa, no entanto, pode ser reformulada pela sua divisão em subfunções básicas, formando estruturas de subfunções arranjadas em série ou em paralelo. O próximo passo é encontrar princípios de solução que contenham o efeito físico e a configuração necessária para a realização de uma dada subfunção. As subfunções devem ser representadas por um par verbo/substantivo, indicando o que o sistema técnico deve fazer, por exemplo: estampar na linha, cortar

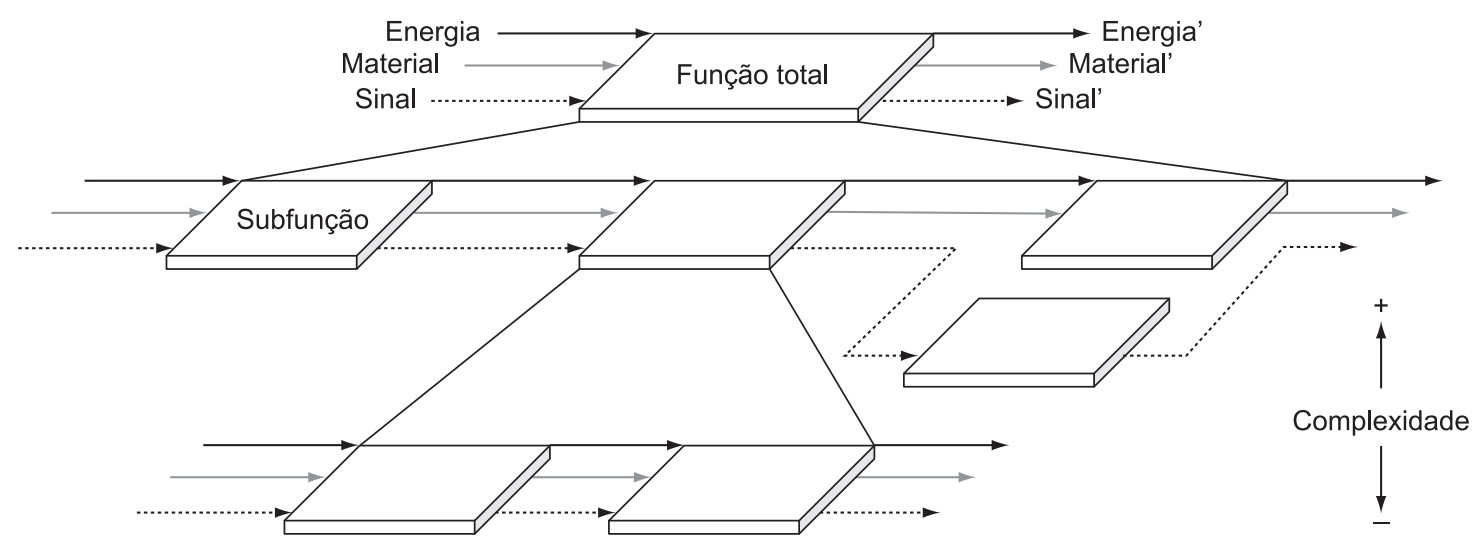

Figura 2. Divisão de uma Função Total em Subfunções. Fonte: Adaptado de Pahl et al. (2005). 
aparas, eliminar refugos etc. Feito isso, parte-se para a busca dos princípios de funcionamento de cada subfunção, identificando as formas que regem seus pares entrada/saída (energia, movimento, força aplicada, dispositivo utilizado etc.). Nesse momento, os princípios de funcionamento são alocados em portadores de função que são componentes físicos que comportam uma única subfunção ou grupo delas, materializando os princípios de funcionamento planejados. Etapa em que a criatividade e o repertório do projetista são evocados com mais ênfase dentro da sistemática.

Tendo-se a concepção inicial, encontrada na fase anterior, pode-se então passar para a fase de Projeto Preliminar ou Anteprojeto, no qual essa concepção prossegue até que se encontre um projeto preliminar para o produto. É um processo complexo, no qual muitas atividades são executadas simultaneamente, utilizando processos iterativos. Alguns pontos devem ser abordados e alcançados nesta etapa sendo alguns deles: identificação de requisitos determinantes, a partir da lista de requisitos, formalizada na primeira etapa da metodologia; avaliação de anteprojetos preliminares por meio de critérios preestabelecidos, de acordo com o julgamento do projetista, selecionando um ou mais de um; detalhamento dos anteprojetos selecionados, avaliando também sua viabilidade técnica e econômica, chegando-se assim, ao projeto básico global preliminar. Por fim, deve-se elaborar a lista de peças preliminares e as instruções preliminares para produção e montagem.

Na última etapa, Projeto Detalhado, faz-se a revisão de tudo que foi proposto pelo projeto preliminar, na busca da definição sobre materiais utilizados, formas de produção e utilização, componentes, acabamento das superfícies, bem como da estrutura de custos, criando assim a documentação obrigatória de desenho e afins para sua realização material e sua utilização.

O modelo chega apenas até a liberação do produto para produção, tida como uma solução. Isso fecha o foco nas etapas de planejamento e concepção do produto, cabendo às teorias e técnicas existentes no mundo empresarial, desenvolver, da melhor forma possível os meios de produção, as ferramentas utilizadas, as pessoas escolhidas e tudo mais que tange à fabricação do produto.

\section{Procedimentos metodológicos}

Uma pesquisa prévia sobre o planejamento de produtos forneceu uma boa base para que se fizesse uma relação entre acidentes, produtos e seu processo de planejamento. Dessa pesquisa, também foi possível perceber a relevância do Modelo estudado e a abrangência que ele tem, não apenas no meio acadêmico, mas também em aplicações empíricas.

Escolhido o Método de Gerhard Pahl e Wolfgang Beitz (PAHL et al., 2005) para o planejamento de novos produtos, como aquele que seria analisado, estudaram-se a fundo suas etapas, utilizando a bibliografia escrita por esses autores - Projeto na engenharia: fundamentos do desenvolvimento eficaz de produtos, métodos e aplicações - e outros livros, dissertações, teses e artigos que fazem referência a tal.

Promoveu-se uma primeira análise, superficial, do método. A partir dela, conseguiu-se identificar alguns pontos como passíveis de melhoria quanto à segurança do usuário dos produtos que seriam desenvolvidos utilizando esse modelo. Posteriormente, uma nova análise foi realizada, desta vez somente com os pontos encontrados na primeira análise e em um grau de observação mais apurado. A justificativa para a escolha dos pontos foi embasada em definições, citações e exemplos de outros autores e pesquisadores que trabalham essa temática. Assim, obtiveram-se justificativas para a seleção de cada um desses pontos que foram apresentados.

Desse estudo inicial, puderam ser elencados pontos de congruência com outros métodos e observar, a partir das pesquisas que também estudaram o Método de Gerhard Pahl e Wolfgang Beitz, problemas ou falhas de ordem conceitual.

Todas as etapas foram estudadas, observando, principalmente, pontos que poderiam ser melhorados, em primeiro momento no que tange à fluidez das etapas e sua possibilidade de realização. Partiu-se, então, para uma análise mais minuciosa, com foco totalmente voltado para as questões de segurança daqueles que utilizarão os produtos desenvolvidos por meio desse método. Estes pontos foram apresentados, juntamente com as causas de serem vistos como passíveis de melhorias.

\section{Resultados}

Desta análise de discurso da metodologia estudada, alguns pontos foram observados como incompletos, vagos, incoerentes ou mesmo passíveis de melhoria quanto à segurança que os produtos por ela desenvolvidos ofereceriam a seus usuários. Estes pontos, juntamente com uma descrição dos motivos que os fizeram ser considerados inadequados, serão apresentados a seguir.

$\mathbf{1}^{\circ}$ Ponto: Muito é falado na metodologia sobre o foco do planejamento nas vontades do cliente, porém, muitas vezes ele próprio não torna explícita sua necessidade de segurança.

Essa característica não deve nortear o planejamento, afinal, o usuário pode não exigir segurança, porém deve adquirir produtos seguros. $\mathrm{O}$ fato de não citar a segurança como requisito, pode ser devido a fatores como não conhecimento apropriado dos itens de segurança ou mesmo o fato de encarar a segurança como fator intrínseco a qualquer produto, independente de ser ou não necessidade sua. Os próprios autores 
apresentam como requisitos implícitos aqueles que não são citados pelos clientes e que, por outro lado, têm efeitos muito negativos quando não são atendidos. São aqueles que seu atendimento é considerado natural (PAHL et al., 2005). Análogo ao que Hill (1989) aponta como qualificadores, ou seja, elementos ou características mínimas que uma Empresa ou seus produtos devem ter para ser qualificados a ser uma fonte ou fornecedor potencial.

É proposto um procedimento para abordar a importância do foco no cliente que parte da atual serventia do produto - papel atribuído somente às suas funções principais - exigida pelo cliente, passa pela previsão de como essa serventia mudará no futuro e, por fim, essas exigências são associadas a portadores de função - subconjuntos ou componentes dos produtos - existentes ou que deverão ser criados. Volta-se ao problema anterior. Para o usuário, na maioria dos produtos, a sua segurança não é serventia. Portanto, cabe ao projetista e aos envolvidos no planejamento do produto, transformar a serventia ou função segurança em portadores de função, mesmo que para isso seja necessário criá-los. Correia, Franklin e Soares (2004) reforçam essa necessidade de abertura do leque de opções do planejamento de produtos. Para eles, pensar que um produto, seja ele de consumo ou não, é desenvolvido apenas objetivando suprir as necessidades primárias dos usuários, pode torná-lo bastante limitado no atendimento às aspirações de uso e status dos consumidores. Poucos são os produtos em que segurança é item de observação por parte dos usuários.

$2^{\mathbf{0}}$ Ponto: No processo de seleção e avaliação de soluções para problemas, da metodos de estudo, utiliza-se uma lista para seleção sistemática, na qual a segurança no produto é critério preferencial e não eliminatório.

Um dos critérios, dentre sete, utilizados na seleção de soluções para o atendimento de uma necessidade, é: Observadas medidas de segurança direta. Esse critério determina apenas se uma solução é preferível a outras, não sendo responsável por eliminar uma solução caso ela, por exemplo, não atenda a essas medidas. É preciso que se entenda, primeiramente, o que os autores consideram como segurança direta. Para Pahl et al. (2005), a tecnologia que utiliza este conceito é aquela que de antemão, e por si mesma, não possua nenhuma periculosidade. Já a tecnologia de segurança indireta lida diretamente com sistemas protetores e a distribuição de equipamentos de segurança.

Além da observância de medidas de segurança direta ser um fator apenas preferencial, sem poder de decisão, é omitida a segurança indireta, que deveria também ser um critério eliminatório, até mesmo pelo que apresentam os próprios autores do método quando dizem que o foco deve ser a segurança direta, porém, quando ela não puder ser atendida, utiliza-se a indireta. Não se deveria descartar, logo de início, a segurança indireta, como o faz a lista de seleção.

$3^{\mathbf{0}}$ Ponto: Na elaboração da lista de requisitos, sugere-se utilizar a técnica do cenário, na qual serão questionadas as reações que o produto terá caso alguma situação se desenvolva, durante todo o seu ciclo de vida.

A técnica de cenários, bastante utilizada nas mais diversas áreas (ambiental, econômica, política etc.), tem por objetivo prever uma situação futura, propiciando a antecipação de ações e medidas a serem tomadas ainda no presente. E, especificamente na área ligada à segurança do usuário, este tipo de análise deveria envolver ferramentas que oferecessem subsídios para tornar a técnica de cenários confiável. Por exemplo, projetar cenários que antevejam as mais variadas formas de utilização do produto, por parte do usuário. As consequências destas formas de utilização podem levar a acidentes. O estudo das consequências desse uso pode ser quantificado pela utilização, por exemplo, da Análise da Árvore de Causas, inclusive probabilisticamente.

$4^{\mathbf{0}}$ Ponto: Nas características de avaliação, meio ambiente está junto com segurança.

Escolhidas as soluções, a metodologia segue com o desenvolvimento de critérios para avaliar a concepção do produto. Uma lista de critérios é apresentada no Quadro 1, porém, com um problema. A característica Segurança divide espaço com Meio Ambiente. Isso pode parcelar a atenção daquele que monta os critérios de avaliação, ou até mesmo, fazê-lo deixar de lado a Segurança e pensar apenas no Meio Ambiente.

Avaliar um projeto quanto à segurança que ele oferecerá ao seu usuário é muito diferente de avaliá-lo quanto à segurança ao Meio Ambiente (não agressão aos recursos naturais, uso de materiais reciclados e recicláveis, projetos de destinação pós-uso etc.). Portanto, o atendimento de um critério de avaliação para uma destas áreas - Segurança e Meio Ambiente não implicará, obrigatoriamente, no atendimento para a outra área. A substituição de uma energia potencialmente perigosa, como a elétrica, por uma mais segura, como a química, presente em baterias, atende ao critério: Disponibilizar fonte de energia segura ao usuário. Porém, um critério mais voltado ao Meio Ambiente, como: Indicar instruções para descarte pós-uso (Logística Reversa), pode não ser atendido, caso o produto não possua informações de onde, quando e como depositar a bateria, quando sua vida útil acabar. Reforçando a necessidade de divisão destes dois conceitos, Carpes Junior e Sell (2006b) apresentam as definições de riscos ambientais e operacionais, que aclaram a disjunção aqui proposta entre estes conceitos. Para eles, os riscos operacionais advêm da interação entre homens e máquinas e estão diretamente ligados a erros na operação, manutenção 
Quadro 1. Características principais para avaliação na fase de concepção.

\begin{tabular}{|ll|}
\hline Característica principal & \multicolumn{1}{c|}{ Exemplo } \\
Função & $\begin{array}{l}\text { Características de portadores de funções auxiliares essenciais, que resultam } \\
\text { naturalmente do princípio de solução escolhido ou da variante de conceito. }\end{array}$ \\
Forma do corpo & $\begin{array}{l}\text { Pequeno número de componentes, pouca complexidade, demanda de espaço reduzida. } \\
\text { Segurança }\end{array}$ \\
$\begin{array}{l}\text { Preferência por medidas diretas de segurança (já seguras pela própria natureza), } \\
\text { desnecessárias precauções adicionais de segurança, garantia de segurança do trabalho } \\
\text { e do meio ambiente. }\end{array}$ \\
\hline
\end{tabular}

e limpeza. Já o grupo de riscos ambientais consiste de eventuais alterações ou modificações no desempenho do produto que pode apresentar, devido a anomalias meteorológicas ou discrepâncias entre o ambiente previsto durante a fase de concepção e do ambiente atual. Os riscos de operação, juntamente com os riscos do produto, ou seja, as características físicas, químicas e biológicas presentes neles, seriam avaliadas, na fase de planejamento de um produto, como características ligadas à segurança, já os riscos ambientais, ao meio ambiente.

$5^{\circ}$ Ponto: Em um exemplo - concepção de um misturador de água de uso doméstico - presente no livro, quase nada foi mencionado sobre segurança para os usuários.

Neste exemplo, tem-se como conversão principal um fluxo de matéria, em que um misturador monocomando permite ajustar a vazão e a temperatura da água, de forma independente, ou seja, o ajuste não mutuamente influenciável (PAHL et al., 2005).

A única menção que é feita, no exemplo, a itens e preocupações ligadas à segurança está na lista de requisitos - a espinha dorsal do projeto - em que deverão constar as exigências a que o produto deve atender e suas características. As únicas referências que se encontram são:

- sem curto-circuito na saída da água;

- temperatura de comando não deve passar dos $35^{\circ} \mathrm{C}$;

- sem queimaduras ao tocar nos acessórios; e

- prever proteção contra queimaduras, se o custo adicional for baixo.

Primeiramente, a temperatura máxima requerida ao dispositivo deveria estar baseada em testes, normas ou leis que garantissem que a esta temperatura não haveria qualquer risco de queimadura para quaisquer tipos de pele, porém, nada foi mencionado quanto a isso. Apenas se colocou esse valor sem que se dissesse sua origem e justificativa. Mais do que isso, se o comando estivesse a $35^{\circ} \mathrm{C}$, muito provavelmente a água estaria a uma temperatura superior, pelo princípio da condução - troca térmica, ocorrida entre os corpos através de um meio sólido que esteja em contato (ARAÚJO; REGAZZI, 2002) - podendo provocar uma queimadura em quem estivesse utilizando-a. O mínimo que deveria existir no produto seria uma indicação clara e simples da possibilidade de saída de água nesta temperatura. Os produtos, nos quais uma função de risco deve ser operada, devem ser estudados e projetados de tal maneira que a pessoa encarregada conheça o risco e atue concentrado e ciente da importância do seu ato (GUBER, 1998).

Esta exigência de identificação dos riscos do produto, por sinal, não se faz presente em nenhum momento no método. Algo que poderia ser facilmente melhorado, caso fosse exigida, por exemplo, a utilização de um indicador para tal, como apresentado por Borges e Rodrigues (2007) no Índice de Informação de Riscos (IIR) que visa quantificar quão bem representadas estão as informações dos riscos intrínsecos ao produto, seja no manual ou no próprio produto. É expresso na Equação 1:

$$
I I R=\frac{\begin{array}{c}
\text { Risco intrínseco ao produto, } \\
\text { informados em seu manual } \\
\text { ou nele próprio }
\end{array}}{\begin{array}{c}
\text { Riscos intrinsecos } \\
\text { existentes no produto }
\end{array}}
$$

O ideal seria que este índice tivesse sempre o valor um, assim, estariam os consumidores devidamente alertados, para todos os riscos que não puderem ser eliminados, por serem da natureza do produto.

Outra observação pode ser feita, talvez mais grave, por expor além da despreocupação com segurança, a sobreposição desta pela questão econômica. Um dos requisitos é: Prever proteção contra queimaduras, se o custo adicional for baixo (PAHL et al., 2005). Já que se pensou, em algum momento, nesta proteção, por que não estudar sua real necessidade a partir de princípios técnicos e não aqueles meramente econômicos? O custo de um possível acidente, para a empresa, pode ser maior do que o custo de prever de antemão uma proteção ao produto. O requisito é contraditório com o próprio discurso dos autores. Para eles, os condicionantes econômicos não deveriam impedir o atendimento de um requisito de segurança (PAHL et al., 2005). 
$6^{\mathbf{0}}$ Ponto: No exemplo - banco de ensaio para cargas de impacto - o que se coloca na lista de requisitos não é específico para a segurança do usuário contra acidentes.

Um dos tópicos abordados na lista de requisitos é: Segurança e Ergonomia. É indiscutível a estreita relação entre os conceitos dessas duas áreas, porém, para a definição dos requisitos necessários a um produto, dever-se-ia desmembrar os dois conceitos, o que tornaria a busca de necessidades a serem atendidas, mais eficiente.

$\mathrm{O}$ cabo de uma máquina furadeira manual seria mais agradável, caso a pega que ele oferece fosse mais anatômica, feita de um material mais confortável. No entanto, isso não melhoraria a segurança para o usuário. Feita apenas essa alteração, o risco da broca se soltar do mandril e atingi-lo ou quem estivesse próximo não seria diminuído. Não necessariamente uma solução em um destes campos trará benefícios ao outro. Assim, essas duas áreas, segurança e ergonomia deveriam ser abordadas em requisitos distintos, otimizando, sua análise e proposta de requisitos para o produto.

$7^{\circ}$ Ponto: Já a lista de verificação das características para o projeto da forma é muito abrangente quanto à segurança.

É perguntado apenas se foram considerados os fatores que influenciam a segurança dos componentes, da função, da operação e do meio ambiente. Deverse-iam atribuir parâmetros mínimos, metas, normas e regras por princípios de segurança. O Quadro 2 apresenta parte da lista de verificação com as principais características para o projeto de forma.

Perguntar se foram considerados os fatores que influenciam a segurança dos componentes, da função, da operação e do meio ambiente, deixa uma lacuna muito perigosa no desenho e projeto material do modelo do produto. Mais uma vez, fica a dúvida a respeito das fontes que fundamentaram esses fatores que deveriam ser considerados

Mais do que, simplesmente, considerados terminologia que abre espaço para respostas objetivas, como: sim ou não - deveriam ser exigidos fatores que garantissem a segurança e não apenas que a influenciassem.

E, como é uma fase em que portadores de função poderão, eventualmente, ser testados, uma ferramenta pode oferecer ótimos parâmetros para uma verificação mais apurada e realista da segurança oferecida pelo produto. São os chamados testes de vida acelerados, utilizados para determinação de níveis de confiabilidade de um produto. Esta confiabilidade é aferida submetendo cada portador de função a condições controladas que reproduzem as reais, num espaço bem menor de tempo do que o necessário para um desgaste real. Fator importante já que a segurança contra acidentes ou panes caminha em conformidade com a confiabilidade (PAHL et al., 2005). Para Teixeira (2004), as vantagens dos ensaios acelerados, além do tempo e custo reduzido, são realmente a comodidade da coleta dos dados e a certeza de que amostras podem ser submetidas comparativamente às mesmas condições de estresse, o que é muito difícil de garantir em campo.

$8^{\circ}$ Ponto: Eles afirmam que uma segurança excessiva pode originar uma grande complexidade que, devido à inexistência de clareza, pode inclusive levar a um declínio da segurança.

Não há necessidade de a segurança ser entendida pelo usuário. Ela deve estar presente no produto, por mais complexa que seja. $\mathrm{O}$ perfeito entendimento deve estar, sim, presente no funcionamento e utilização do produto.

Sensores, aparelhos, chips e tantos outros componentes utilizados para garantir níveis aceitáveis de segurança ou mesmo proteger pessoas dos mais diversos riscos, não têm de, obrigatoriamente, ser entendidos por quem deles faz uso. Muitas vezes, estes componentes não são nem vistos e em outras, sua existência nem é conhecida. Já a função que eles desempenham, esta sim, deve existir. A segurança excessiva e a grande complexidade por ela gerada, só poderiam ser responsáveis pelo declínio da segurança, caso se tivesse de manusear ou entender o dispositivo utilizado para oferecer segurança ao usuário, como

Quadro 2. Lista de verificação com as principais características para o projeto da forma (Parte dela).

\begin{tabular}{|c|c|}
\hline Característica principal & Exemplos \\
\hline Função & A função prevista é satisfeita? Quais funções auxiliares são necessárias? \\
\hline Princípio de trabalho & $\begin{array}{l}\text { Os princípios de trabalho selecionados oferecem o efeito desejado, grau de eficiência e } \\
\text { vantagem? Quais distúrbios devem ser observados? }\end{array}$ \\
\hline Dimensionamento & $\begin{array}{l}\text { A forma e dimensões selecionadas garantem, com o material previsto e com (projeto) } \\
\text { antecipado tempo de vida útil e sob as cargas de serviço, ter suficiente durabilidade? } \\
\text { Deformações admissíveis? Suficiente estabilidade? Suficiente independência de } \\
\text { ressonância? Dilatação desacompanhada de distúrbios? Resistências à corrosão e ao } \\
\text { desgaste aceitáveis? }\end{array}$ \\
\hline Segurança & $\begin{array}{l}\text { Foram considerados os fatores que influenciam a segurança dos componentes, da } \\
\text { função e do meio ambiente? }\end{array}$ \\
\hline
\end{tabular}


seria o caso de um capacete muito difícil de se ajustar ou mesmo travas de segurança difíceis de fechar. Um operador de máquina injetora de plástico não precisa entender o sistema mecatrônico que existe por trás do acionamento bimanual de sua porta de segurança. Basta que ele saiba que, para que a porta feche e a máquina injete o plástico no molde, ele necessita acionar dois botões, um com cada mão e ao mesmo tempo.

$9^{\circ}$ Ponto: Eles utilizam um conceito muito arriscado, o de risco-limite.

O risco-limite seria, de acordo com os autores, o maior risco aceitável, específico da instalação de um determinado processo ou de uma de suas fases. Eles consideram a segurança como sendo a condição na qual o risco é menor que o risco-limite. Mas como se pode aferir o risco-limite? É um limite extremamente difícil de ser encontrado. Do ponto de vista prevencionista, é uma situação perigosa.

Dever-se-ia trabalhar para que não existisse risco algum. Caso isso não fosse possível, aí sim, pensarse-ia em formas de minimizar os riscos, isolá-los ou mesmo proteger as pessoas contra o risco existente. Aceitar, de imediato, que o risco poderá existir, desde que seja até um risco-limite, é negligenciar a possibilidade de se elencar os riscos existentes, de forma prática, e eliminá-los ou, no mínimo, combatê-los.

$\mathbf{1 0}^{\circ}$ Ponto: Eles citam que uma solução pode ser abortada se o nível de segurança alcançado for insatisfatório.

Mas não deixam claro que nível é esse, de onde parte, quem o especifica etc. Caso o $9^{\circ}$ ponto fosse solucionado, ou seja, existissem parâmetros concisos, bem detalhados e valores confiáveis, isso poderia fundamentar o conceito apresentado neste $10^{\circ}$ ponto. Um valor estudado, avaliado, mensurado e não apenas citado teoricamente, que pudesse, inclusive, definir entre abortar ou prosseguir com uma dada solução. No entanto, o $10^{\circ}$ ponto, só agrava essa inexatidão. Em um dado momento, confirmam isso, quando respondem a uma dúvida que poderia, segundo eles próprios, surgir, a saber: não seria melhor desistir de uma concretização, considerando que o nível de segurança alcançado é aparentemente insatisfatório? Eles respondem dizendo que isso vai depender do nível de segurança alcançado, da probabilidade de influências geradoras de acidentes, danosas ou não neutralizadas pelo objeto, e suas prováveis consequências (PAHL et al., 2005).

Em suma, condiciona-se a desistência de uma solução a uma probabilidade. Mas, probabilidade em que nível? Se a probabilidade existe, essas influências deveriam ser eliminadas ou mitigadas a níveis seguros, bem definidos, conforme sugerido nos $9^{\circ}$ e $10^{\circ}$ pontos. Não é prudente, por menor que seja esta probabilidade, aceitar uma solução que apresente qualquer tipo de influência negativa à segurança ou ofereça algum risco ao usuário.

$1^{\circ}$ Ponto: Nada é apresentado ou citado sobre a forma como o usuário utiliza o produto, ou seja, se ele utiliza corretamente, como foi planejado.

Isso é um fator importante que deveria ser bastante analisado durante o planejamento. A possibilidade de variação no uso. Cabendo aqui até mesmo uma análise de cenários, com possíveis utilizações do produto por parte do usuário e as consequências de cada atitude.

Muitos dos acidentes, atribuídos a erros humanos, têm sua gênese na possibilidade de operacionalização incorreta do produto. Na verdade, só se pode falar em erro humano quando, num produto, os princípios ergonômicos tiverem sido aplicados adequadamente e o usuário tiver sido devidamente instruído e treinado em condições reais, respeitando-se as capacidades e limitações humanas (NELSON; ASSOCIATES, 2007) e, mesmo assim, este tiver um comportamento diverso do padrão esperado. Quando as limitações humanas não forem consideradas satisfatoriamente no projeto de um produto, tem-se um projeto deficiente (CARPES JUNIOR; SELL, 2006a).

\section{Conclusões}

A observação crítica desses pontos passíveis de aprimoramento revela que os problemas aqui encontrados têm, em sua maioria, ligação com a falta de uma visão mais preventiva dos autores. Sendo, assim, fáceis de ser resolvidos, caso se queira partir para uma proposta de melhoria do modelo. Algumas conclusões puderam ser tiradas da avaliação desses pontos.

Primeiro, os autores aceitam a segurança no projeto apenas como item preferencial e não obrigatório, característica perigosa haja vista a responsabilidade que o projeto de produtos tem em relação à segurança dos usuários desses produtos.

Segundo, alguns conceitos deveriam ser separados do conceito de segurança, a fim de focar mais as questões estritas de segurança do produto, como acontece com ergonomia e meio ambiente. A segurança, por si só, apresenta características bastante específicas que a torna uma área que exige atenção aos detalhes e envolve conhecimentos, inclusive de outras áreas, como psicologia, fisiologia e resistência dos materiais.

Além disso, os conceitos, apresentados pelos autores, relacionados à segurança, deveriam ser mais precisos e melhor descritos e não tão abrangentes como se encontra, por vezes, no modelo. Isso pode dar margem a decisões equivocadas, dúbias ou mesmo incorretas. Aceitar, por exemplo, trabalhar com o conceito de risco-limite já oferece uma debilidade inestinguível ao produto concebido. A predisposição dele para transpor o risco-limite e entrar em uma zona 
de perda de controle, na qual o acidente é inevitável (RASMUSSEN, 1994) é fator de degradação do sistema homem-produto.

O reduzido número de pontos propostos a serem melhorados, reforça a importância que o modelo tem, haja vista ser tão robusto e detalhado e apresentar pouca coisa a ser repensada. Ressalte-se aqui, a qualidade na descrição das etapas a serem seguidas dentro do modelo. São fases que apresentam ligação entre si e permitem seguir uma sequência concisa de tarefas no desenvolvimento de um produto. No entanto, não apenas uma preocupação maior com a segurança faz-se necessária, mas outros tópicos, como ergonomia, descarte, adaptação a diferentes mercados, entre outros são pouco avaliados ou simplesmente não o são. A incorporação de diversas lógicas dentro de um projeto de produto - ou qualquer tipo de projeto - é algo que tem sido defendida por Louis Bucciarelli. Para ele, cada pessoa tem um visão, um mundo-objeto, que é formado a partir de suas esperiências, de sua formação e de sua história de vida (BUCCIARELLI, 1994). E para o desenvolvimento satisfatório de um projeto, essas lógicas têm de se equalizar, por meio de construção social. É nesse sentido que a lógica da segurança foi o viés principal desta pesquisa, como uma das lógicas que têm de ser incorporadas em qualquer projeto.

Todos que possuem em sua formação acadêmica, conceitos e princípios de segurança, no mais amplo sentido, têm a responsabilidade de viver constantemente à procura de lacunas nas quais riscos possam existir e expor pessoas ou bens materiais a acidentes. E, acima de tudo, propor, de alguma forma, ações que possam minimizar essas lacunas ou eliminá-las. Assim, o aprimoramento do Método de Gerhard Pahl e Wolfgang Beitz, apresentado como resultado desta pesquisa, é mais um passo nesta constante preocupação com a segurança das pessoas que qualquer um deve ter, mesmo que não seja encarregado formalmente de tal e independente de sua formação.

Não foi objetivo deste estudo, denegrir ou menosprezar o trabalho destes dois renomados projetistas, que idealizaram um método tão consistente e aceito nos meios acadêmico e industrial. Mas, como o conhecimento é falível (LAKATOS; MARCONI, 2001), eternamente incompleto e vive em constante evolução, buscou-se simplesmente propor uma lapidação neste método, pensando no produto como algo que fará parte da vida e do cotidiano de diversas pessoas nos mais variados lugares, tanto a lazer como a trabalho.

Por fim, a identificação dos pontos passíveis de melhoria foi apresentada, como proposto no objetivo desta pesquisa, contudo, ela não deve ser simplesmente adaptada a outros modelos. A pesquisa limitou-se a analisar o Modelo de Gerhard Pahl e Wolfgang Beitz. Para cada caso, deve-se promover uma nova análise, pois as características podem - e até devem - ser bastante diferentes. Assim como os resultados encontrados aqui não são definitivos e indubitáveis. Mas esta pesquisa pode servir de estímulo para outras.

\section{Referências}

ARAUJO, G. M. de; REGAZZI, R. D. Perícia e avaliação de ruídos e calor passo a passo: teoria e prática. 2 . ed. Rio de Janeiro: Isegnet, 2002.

BARAM, M. Liability and its influence on designing for product and process safety. Safety Science, v. 45, n.1-2, p. 11-30, 2007.

BERTALANFFY, K. L. V. General systems theory: foundations, developments, applications. New York: George Braziller, 1969.

BORGES, F. M.; RODRIGUES, C. L. P. Proposta de indicadores de desempenho para a segurança no processo de planejamento de novos produtos. In: CONGRESSO MUNDIAL DE PESQUISAS AMBIENTAIS, SAÚDE E SEGURANÇA, 2007, Santos. Anais... Santos: SHEWC, 2007.

BUCCIARELLI, L. L. Designing engineers. Cambridge: The MIT, 1994.

CARDOSO, O. R. Abordagem sistêmica para o planejamento do produto. 1985.88 p. Dissertação (Mestrado) - Universidade Federal de Santa Catarina, Florianópolis, 1985.

CARPES Jr, W. P.; SELL, I. O produto como causador de acidentes. Revista Produção Online, v. 4. n. 2, $2006 a$.

CARPES Jr, W. P.; SELL, I. Safety needs of product users. Revista Produção Online, v. 4, n. 2, 2006b.

CLARK, K. B.; FUJIMOTO, T. Product development performance: strategy, organization and management in the world auto industry. Boston: HBS Press, 1991.

COOPER, R. G. Winning at new products: accelerating the process form idea to launch. 3. ed. New York: Perseus, 2001.

CORREIA, W.; FRANKLIN, M; SOARES, M. M. Usabilidade, ergonomia e acidentes domésticos: uma análise real com produtos de consumo em uma capital brasileira. In: ENCONTRO NACIONAL DE ENGENHARIA DE PRODUÇÃO, 24., 2004, Florianópolis. Anais... Florianópolis: ENEGEP, 2004.

COSTA, J. I. P. da. Marketing: noções básicas. Florianópolis: Imprensa Universitária, 1987.

COULIBALY, A.; HOUSSIN, R.; MUTEL, B. Maintainability and safety indicators at design stage for mechanical products. Computers in industry, v. 59, n. 5, p. 438-449, 2008.

DILLENBURG, M. R. Estimativas de confiabilidade de produto a partir das contagens mensais de vendas $e$ falhas ao longo do período de garantia. 2005. 93 p. Dissertação (Mestrado) - Universidade Federal do Rio Grande do Sul, Porto Alegre, 2005.

ESTORÍLIO, C; SZNELWAR, L. I. Melhorando o desempenho do desenvolvimento do produto através da análise do processo: um estado de caso. In: CONGRESSO BRASILEIRO DE GESTÃO DE DESENVOLVIMENTO 
DE PRODUTO, 3., 2001, Florianópolis. Anais... Florianópolis: UFSC, 2001.

FONSECA, A. J. H.; NASCIMENTO, M. de S.; PADILHA, J. L. Espiral do desenvolvimento: um modelo utilitário para o processo de desenvolvimento de produtos industriais. In: CONGRESSO BRASILEIRO DE GESTÃO E DESENVOLVIMENTO DE PRODUTOS, 4., 2003, Gramado. Anais... Porto Alegre: CBGDP, 2003.

FORMOSO, C. T.; GUIMARÃES, L. B. de M.; SAURIN, T. A. Integração da segurança no trabalho à etapa de desenvolvimento de produto na construção civil: um estudo exploratório. In: ENCONTRO NACIONAL DE ENGENHARIA DE PRODUÇÃO, 22., 2002, Curitiba. Anais... Curitiba: ABEPRO, 2002.

GOUVINHAS, R. P.; COSTA, P. E. de C. Desenvolvimento de um modelo de gestão do conhecimento para a melhoraria do processo de desenvolvimento de produtos. In: CONGRESSO BRASILEIRO DE GESTÃO E DESENVOLVIMENTO DE PRODUTOS, 4., 2003, Gramado. Anais... Porto Alegre: CBGDP, 2003.

GUBER, N. D. Responsabilidade no projeto do produto: uma contribuição para a melhoria da segurança do produto industrial. 1998. Dissertação (Mestrado) - Universidade Federal de Santa Catarina, Florianópolis, 1998.

HALE, A.; KIRWAN, B.; KJELLÉN, U. Safe by design: where are we now? Safety Science, v. 45, n. 1-2, pp. 305-327, 2007.

HILL, T. Manufacturing strategies: text and cases. Massachussets: Richard Irwin, 1989.

HOFFMEISTER, A. D. Sistematização do processo de planejamento de projetos: definição e seqüenciamento das atividades para o desenvolvimento de produtos industriais. 2003. 120 p. Dissertação (Mestrado) - Universidade Federal de Santa Catarina, Florianópolis, 2003.

KINDLEIN Jr, W.; PLATCHECK, E. R.; CÂNDIDO, L. H. A. Analogia entre as metodologias de desenvolvimento de produto atuais, incluindo a proposta de uma metodologia com ênfase no ecodesign. In: CONGRESSO INTERNACIONAL DE PESQUISA EM DESIGN, 2., 2003, Rio de Janeiro. Anais... Rio de Janeiro, 2003.

KINNERSLEY, S.; ROELEN, A. The contribution of design to accidents. Safety Science, v. 45, n. 1-2, p. 31-60, 2007.

KOTLER, P. Administração de marketing. São Paulo: Atlas, 1998.

KRUGLIANSKAS, I. Engenharia simultânea: organização e implantação em empresas brasileiras. In: SIMPÓSIO NACIONAL DE GESTÃO DA INOVAÇÃO TECNOLÓGICA, 17., 1992, São Paulo. Anais... São Paulo: USP, 1992.

LAKATOS, E. M.; MARCONI, M. de A. Fundamentos da metodologia científica. 4. ed. São Paulo: Atlas, 2001.

LANGERAK, F.; HULTINK, E. J. The effect of new product development acceleration approaches on development speed: a case study. Journal of Engineering and Technology Management, v. 25, n. 3, p. 157-167, 2008.

LÓPEZ-VALCÁRCEL, A. New challenges and opportunities for occupational safety and health (OSH) in a globalized world. Geneva: International Labour Office , 2002.
MAIER, J. R. A.; FADEL, G. M. Affordance based design: a relational theory for design. Research in Engineering Design, v. 20, n. 1, p. 13-27, 2009.

MARINI, V. K.; ROMANO, L. N. Influencing factors in agricultural machinery design. Product: Management \& Development, v. 7, n. 2, p. 111-130, 2009

MASLOW, A. H. Motivation and personality. 2. ed. New York: Harperg Row, 1970.

MENDES, L. A.; BACK, N.; OLIVEIRA, G. H. C. Designing automated test systems: an adapted methodology inspired on Pahl and Beitz's systematic approach. Robotics and Computer-Integrated Manufacturing, v. 25, n. 6, p. 945-950, 2009.

MENDEZ, S;. I. Um método para o desenvolvimento de produtos alimentícios aplicado em uma indústria avícola. 2004. Dissertação (Mestrado) - Universidade Federal de Santa Catarina., Florianópolis, 2004.

NELSON \& ASSOCIATES. Core principles of safety engineering and the cardinal rules of hazard control. Disponível em: <http://www.hazardcontrol.com/ coreprinciples.html.>. Acesso em: 28 de set. de 2007.

PAHL, G. et al. Projeto na engenharia: fundamentos do desenvolvimento eficaz de produtos, métodos e aplicações. São Paulo: Edgard Blucher, 2005. 411 p.

RASMUSSEN, J. Risk management, adaptation and design for safety. In: BREHMER, B.; SAHLIN, N. E. Future risks and risk management. New York: Springer, 1994.

RAUSAND, M.; UTNE, I. B. Product safety: principles and practices in a life cycle perspective. Safety Science, v. 47, n. 7, p. 939-947, 2009.

ROZENFELD, H. Desenvolvimento de produtos na manufatura integrada por computador (CIM). São Carlos: NUMA - USP, 1999.

ROZENFELD, H. et al. Gestão de desenvolvimento de produto: uma referência para a melhoria do processo. São Paulo: Saraiva, 2006.

SELL, I. Segurança do produto. In: ENCONTRO NACIONAL DE ENGENHARIA DE PRODUÇÃO, 12., 1992, São Paulo. Anais... São Paulo: ENEGEP, 1992. p. 423-428.

SICSÚ, A. B.; CORREIA, W. F. M.; SENA, G. C. Responsabilidade empresarial: acidentes versus produtos de consumo. In: ENCONTRO NACIONAL DE ENGENHARIA DE PRODUÇÃO, 26., 2006, Fortaleza. Anais... Fortaleza: ENEGEP, 2006.

TAYLOR, J. R. Statistics of design error in the process industries. Safety Science, v. 45, n.1-2, p. 61-73, 2007.

TEIXEIRA, C. A. R. A confiabilidade como fator de valor na melhoria de produtos. estudo de caso: sistema de embreagem automotiva. 2004. 129 p. Dissertação (Mestrado) - Universidade Estadual de Campinas, Campinas, 2004.

TOLEDO, J. C. de. et al. Fatores críticos de sucesso no gerenciamento de projetos de desenvolvimento de produto em empresas de base tecnológica de pequeno e médio porte. Gestão e Produção, v. 15, n. 1, p. 117-134, 2008.

WRIGHT, J. T. C.; SILVA, A. T. B. da; SPERS, R. G. Popular market: from the future studies to development of products. Future Studies Research Journal, v. 1, n. 1, p. 84-99, 2009. 